Copyright 1910. By A.I.E.E.

\title{
ELECTRIC POWER IN THE CONSTRUCTION OF THE LOS ANGELES AQUEDUCT
}

\author{
BY E. F. SCATTERGOOD
}

The Los Angeles aqueduct extends from the intake in Owens valley, about 12 miles north of the town of Independence, to the storage reservoirs at the head of the San Fernando valley, about 24 miles distant from the city of Los Angeles, from which point the city water department will take care of the distribution of the water. The length of the aqueduct proper is, therefore, 240 miles.

From the southern end north to the north portal of the Elizabeth lake tunnel, a distance of 35 miles, the work is heavy, being to a considerable extent composed of tunnels, including the Elizabeth lake tunnel, some 27,000 ft. in length, through granite rock. Preliminary estimates showed that in such sections the considerable amount of power required could be furnished much more cheaply, from a central generating plant and distributed by high tension transmission, than by small power generating units, either by steam or distillate engines at various points as required. This section is supplied with power purchased from the Southern California Edison Company, and delivered at one of its substations about four miles west of the aqueduct line and near the center of this section. From the Elizabeth lake tunnel to a point 55 miles further north, the aqueduct follows along the desert in the open, and estimates indicated that the conduit excavation, and concrete work of lining and cover, could be done more cheaply with the use of steam shovels and gas engines than by the erection of a temporary electrical generating and distributing system. From the Pinto hills north to the intake, a distance of 150 miles, there are 
alternate sections of the heavy tunnel work and of the lighter conduit work. In the Owens valley there are numerous creeks flowing down the eastern slope of the Sierra Nevada mountains offering excellent opportunities for power in sufficient quantities for construction work on the aqueduct; and estimates showed clearly that power could be developed at these creeks and transmitted along this 150 miles, and delivered to all points requiring power, in large or small amounts, at a very much lower cost than that for which it could be furnished in any other way.

It should be stated for the benefit of those who are not so familiar with the city's project, and who may read this paper, that the power referred to here is for construction purposes only, and should not be confused in any way with the large amount of electric power which may be developed along the line of the aqueduct when it is in operation, and which will total a peak load capacity of 120,000 h.p. delivered at step-down voltage in the city.

\section{Power System}

For the purpose of supplying power along the section of the aqueduct from the intake to the Pinto hills, hydroelectric plants were installed on Division and Cottonwood creeks. The Division creek plant is about three miles south from the aqueduct intake, and has a rated capacity of $600 \mathrm{kw}$. The works at the point of diversion at the creek cost $\$ 1,214$. The penstock starting from this point, and extending down the slope 10,500 ft., consists of $6,291 \mathrm{ft}$. of 18 -in. riveted pipe and $4,209 \mathrm{ft}$. of 15 -in. lapwelded pipe, and cost, in place, $\$ 28,102$. The effective head obtained is approximately 1,200 ft. The power house equipment consists of one tangential wheel direct connected to a 2200-volt, three-phase, 600-rev. per min. generator and a bank of transformers, stepping the voltage up to 33,000 , each of which has a continuous overload capacity of 25 per cent above the $600-\mathrm{kw}$. rating. The power house is built of concrete in a substantial manner. This is also true of the second one to be described, as these plants are intended to become a part of the permanent aqueduct power system. The cost of the power house and equipment, including three cottages, etc., is $\$ 21,100$, making a total cost of approximately $\$ 84.50$ per $\mathrm{kw}$., or $\$ 63$ per h.p. rated capacity at the switchboard.

The Cottonwood power house is approximately 40 miles south from the Division creek plant. Its equipment consists of two tangential wheels, operated under 1,200 ft. effective head, 
each direct connected to a 750-kw. three-phase, 2200-volt, 600 -rev. per min., generator, each of which in turn is connected to the 33,000 -volt line through a separate bank of transformers. The works at the diversion point cost $\$ 3,964$. The canyon for a distance of $3,750 \mathrm{ft}$. is so precipitous as to make a conduit or tunnel impracticable within reasonable cost, therefore, a 24 -in., No. 12 gauge, riveted pipe was buried along the side of the canyon, at a cost of $\$ 9,352$. From this point to the forebay, a distance of $7,042 \mathrm{ft}$., a covered concrete conduit, $30 \mathrm{in}$. by $20 \mathrm{in}$. inside section, was constructed on the mountain side at a cost of $\$ 11,228$. The penstock, with $523 \mathrm{ft}$. of 24 -in. pipe and 4,009

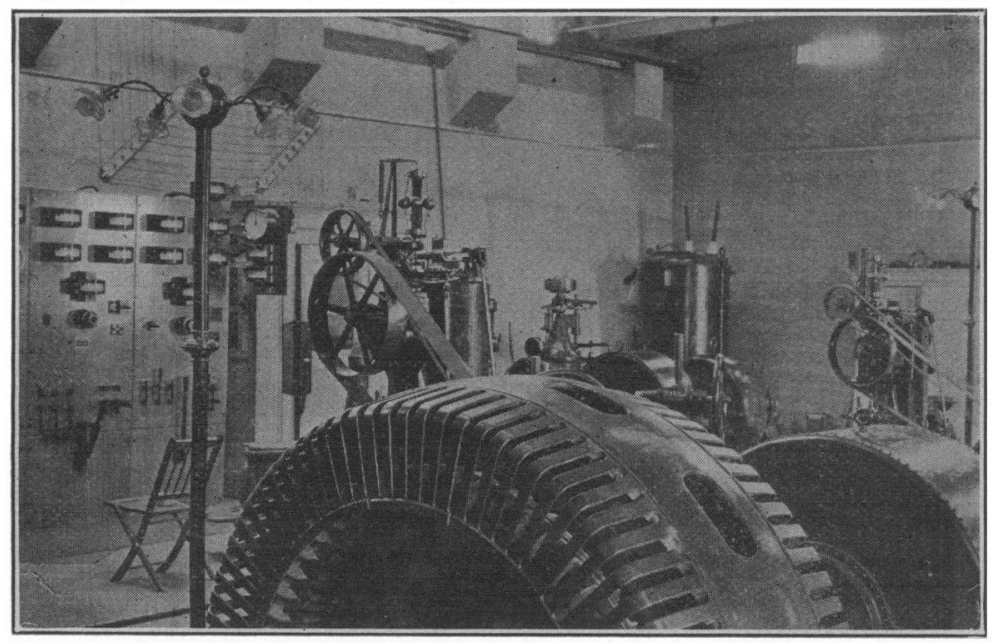

Cottonwood power house - two 750-kw. generators-power all utilized for construction work

ft. of 22 -in. pipe, or a total of $4,532 \mathrm{ft}$., cost $\$ 29,820$. The power house and camp complete cost $\$ 49,638$, making a total of $\$ 69.40$ per kw., or $\$ 51.75$ per h.p. of rated capacity at the switchboard, the plant having 25 per cent overload capacity.

The transmission line is 151 miles long, and is made up of three No. 4 bare copper wires; two-part seven-inch porcelain insulators with iron thimbles, pins and bases; one wire on a 15-in. crossarm at the top of a 30-ft. pole, and two on a 6 -ft. crossarm below, and poles spaced $180 \mathrm{ft}$. apart. The average cost of this line is $\$ 862.50$ per mile. About one-fifth of this line is through rough mountainous country, and the wagon haul for 
the entire line an average of 12 to 15 miles. This line has since been extended from its southern end to the aqueduct cement plant, a distance of 17 miles, with No. 2 copper, at a cost of $\$ 1,050$ per mile. The object of this extension is to deliver surplus power to the cement plant, with the advantage of supplementing the steam plant, thus saving fuel oil and making the entire system more flexible and reliable by running in parallel with two $750-\mathrm{kw}$. steam turbines at that point. Had the cement plant been contemplated originally, more copper might have been used along the whole line, and more generating capacity installed to advantage. As an interesting illustration of the

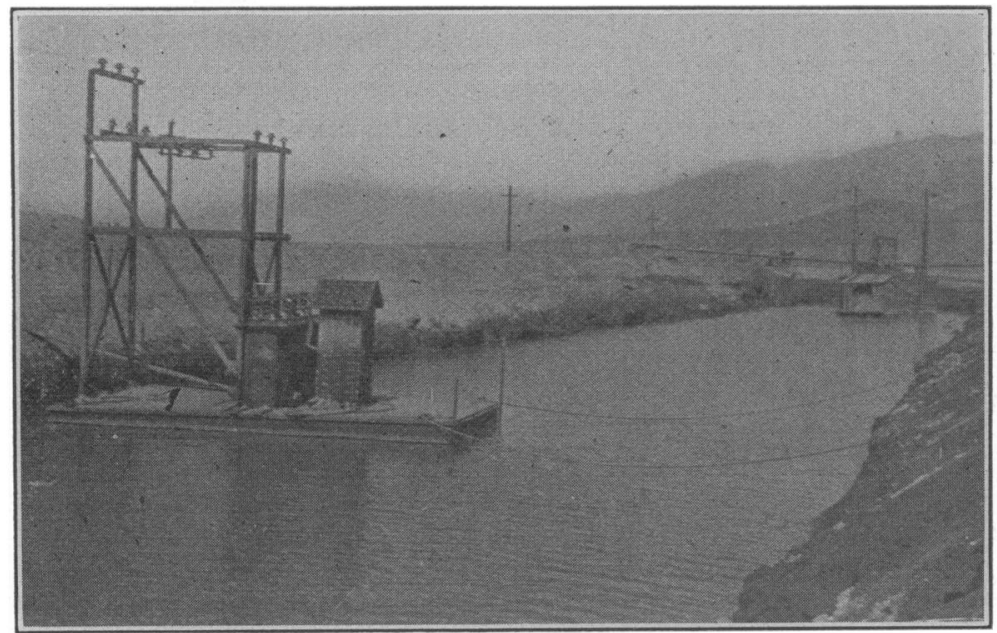

Floating transformer station used in connection with suction dredge; Owens Valley

value of synchronous condensers in connection with transmission of electric power, it may be stated that while delivering a distributed load of $1000 \mathrm{kw}$. between the intake and the Pinto hills, 400 to $420 \mathrm{kw}$. could be delivered at the cement plant, 125 miles from Cottonwood at 30,000 volts with 35,000 volts at Cottonwood when not in parallel with the steam turbines; and that $800 \mathrm{kw}$. can be delivered at the cement plant when running in parallel, by strengthening the field of the turbogenerators, with the same voltage drop and the same distributed load along the line.

There are about 74 step-down transformers connected to this line in banks of two or three; most of these transformers are of 
$40 \mathrm{kw}$. capacity, the remainder are either $20-\mathrm{kw}$. or $80-\mathrm{kw}$. The greater number are of the out-door type, which have given excellent satisfaction, and are very much liked by the men in charge of work, because of the decreased expense and time of setting them up. Most of them have been shipped from the factory with the oil in them, as they are in boiler iron cases, made suitable for moving with the oil in place, thus avoiding the necessity for drying out of transformers at isolated places. The protection of this high-tension line against lightning and surge voltages is a combination of low-equivalent arresters at the Cottonwood power house and three sets of horn-gap arresters at other important places. The transformer stations are protected by air-insulated choke coils and fused horn-gap switches. The comparatively small insulators for the voltage used, while they have given no trouble whatever, do undoubtedly serve to give additional protection to apparatus along the line by affording relief from any excessive potential. No apparatus has been lost from lightning or surges during the eighteen months of its operation.

By including interest, placing a proper depreciation on the permanent power plant, and assuming a low value of return from the copper on the temporary line, and on the transformers constituting the substations, (the system to be in use but four years), it was estimated that the cost per kilowatt hour delivered at a step-down voltage, in large and small quantities as desired, would be approximately 1.15 cents. The indications are that this estimate will prove to have been conservative.

\section{Uses of Electric Power}

Stating as briefly as possible the uses to which this power is put; there are in Owens valley about 20 miles of the aqueduct which can conveniently be built with dredges. Four electric shovels are in use for conduit excavation in the open country. One mill for regrinding tufa with the cement is located at Haiwee, 22 miles south of Cottonwood. Electric power is used at Haiwee, also for sluicing and other work connected with the building of the earthen dam. There are approximately 18 miles of rock tunnels and three miles of earth tunnels provided for by this power system. The typical tunnel equipment consists of one air compressor, driven by a 100-h.p., 440-volt, three-phase induction motor; one $80-\mathrm{kw}$. motor-generator set, providing 250 -volt direct current for electric locomotives; lighting and 
other work inside the tunnels; other power for blowers, machine shop, hoists, pumping, etc., as the case may be, and for lighting camp. In case electric locomotives are not used, as in shorter tunnels, alternating current at 110 volts is used for lighting in the tunnels also.

Dredges. There are two suction dredges in operation in Owens valley, each equipped with a 12 -inch centrifugal pump, driven by a 100-h.p., 440-volt induction motor; one 40-h.p. motor to run the cutter, one 40-h.p. motor to run the jetting pump for breaking down the bank over the cutter, and one 20-h.p. motor for operating various hoists. There is also one dipper dredge of one and one-half yards capacity, of the friction type, driven

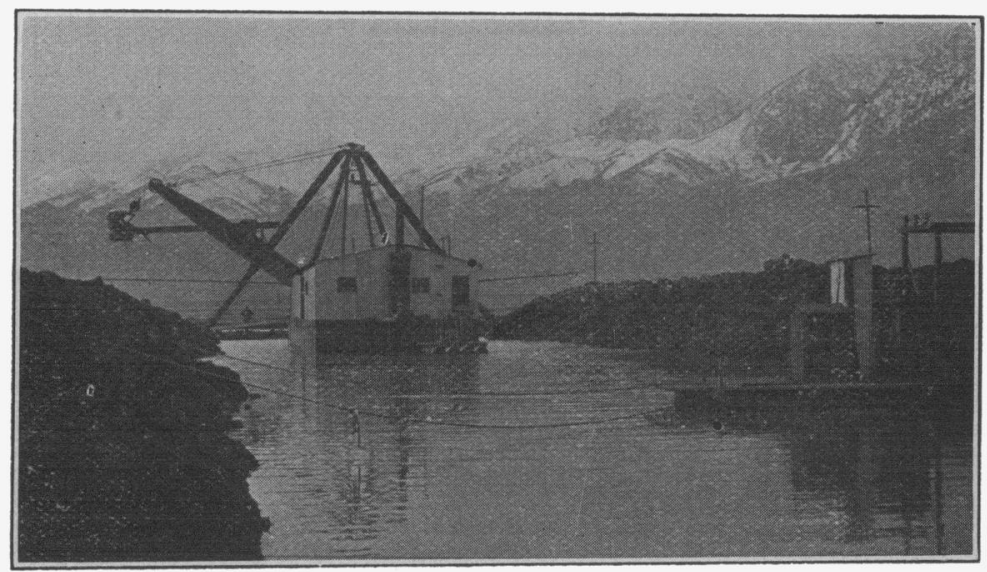

Dipper dredge in Owens Valley

by one 100-h.p. induction motor. The step-down transformers in each case are mounted on a float, with the rack overhead supporting the choke coils and switch on which the taps from the transmission line land. The line being close by requires but one short span, and a crossarm is placed on the round cedar pole by clamping it with two bolts and a short piece on the back, as shown in the illustration, then pushing up at a safe distance from the lower arm. Connection is made with the line through long spiral springs of tempered brass and a brass clip at the end. These are put in place by means of a long pole from an insulating stand, or by climbing a short distance up the power poles, with the line switches at the transformers open, and the transmission line hot, which necessity requires, and which cannot result in 
personal harm when done by an experienced lineman, as is the case. The connection from the transformer float to the dredge is made by means of a three-conductor submarine armored cable. The cable is stored on a reel on a second float attached behind the dredge, with flexible connections to the dredge, so

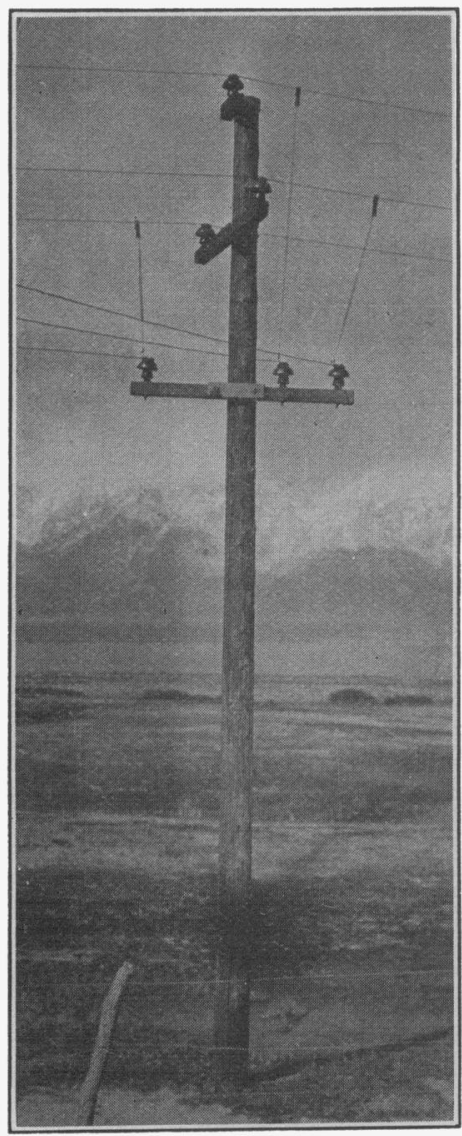

Method of connecting portable substation to 33,000 -volt transmission line that the cable is automatically paid out, and when all out the flexible connections are detached and the cable wound up, then the reel float and the transformer float are towed up to the dredge together. This method has proved very satisfactory in avoiding abuse to the cable and in saving time and expense in moving.

Electric Shovels. Electric shovels with three-quarter yard buckets, and 25-ft. booms, used for conduit excavation, are of the friction type, driven by one 75-h.p., 2200-volt induction motor. The step-down transformers are mounted permanently on sleds or trucks, with the racks supporting the choke coils and switches permanently fixed overhead, and with two 10-kw., 2200- to 440-volt transformers attached, supplying power for concrete mixers operated in connection with each shovel. The cable used is three conductor No. 10 with rubber insulation, rounded out with jute, taped with weather-proof braid and half round steel armor over all. This connects between the transformers and the shovel and between the temporary 440volt line on the power poles (about $1000 \mathrm{ft}$. back from the transformers) and the mixers, and is giving excellent satisfaction. The considerable advantage experienced with the use of out-door type transformers in connection with dredges and shovels is very evident. 
Electric Locomotives. Twelve three-ton electric locomotives rated at $1200 \mathrm{lb}$. draw-bar pull at six miles per hr. are in use in this section of the aqueduct. At each end of the Elizabeth tunnel, which is not supplied from this power system, there is one locomotive of this size and one six-ton locomotive. In that tunnel, which is approximately $90 \mathrm{sq}$. ft. in section when lined, the larger locomotive is preferred, making it possible to pull out 14 to 16 cars of muck at one time. The three-ton locomotives are of good size for the tunnels in the section under consideration, which are approximately $70 \mathrm{sq}$. ft. in finished section, and range from 2000 to $10,000 \mathrm{ft}$. in length where locomotives are used. The use of electric locomotives in these tunnels results

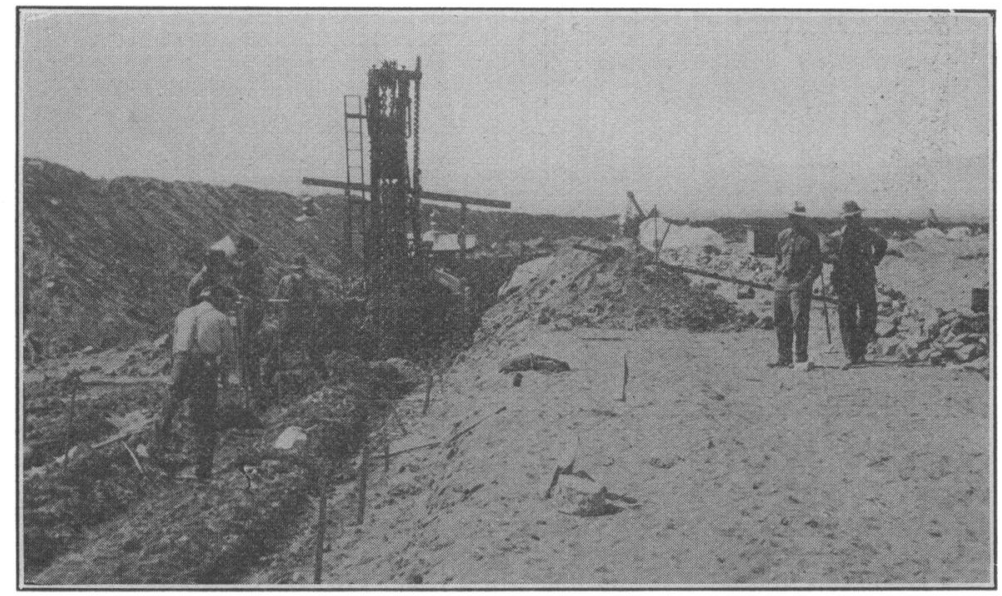

Electric shovel on open conduit; Mojave Valley

in a reduction in cost of excavation and placing the concrete lining, which is a considerable percentage of their total cost. The actual cost of removing muck and delivering concrete is considerably less than it would be if done in other ways, especially by mules; but the greater reduction in cost is due to the practical condition of being able to get the muck away for the convenience and economic working of the miners in excavation, and allowing the placing of rock crushers and concrete mixers at a conveneint point outside of the tunnel for concrete work. Concreting is being done successfully and with perfect satisfaction to the engineers at a distance of 10,000 feet in one instance. This use of these machines makes it possible not only to reduce 
the cost where speed is not a consideration, but to very materially increase the speed, if desired.

Small Isolated Power. Experience with distillate engines in connection with concrete mixers and other small power has led the men in the field to plead for electric power; for example, several steam shovels are in use in this section for conduit

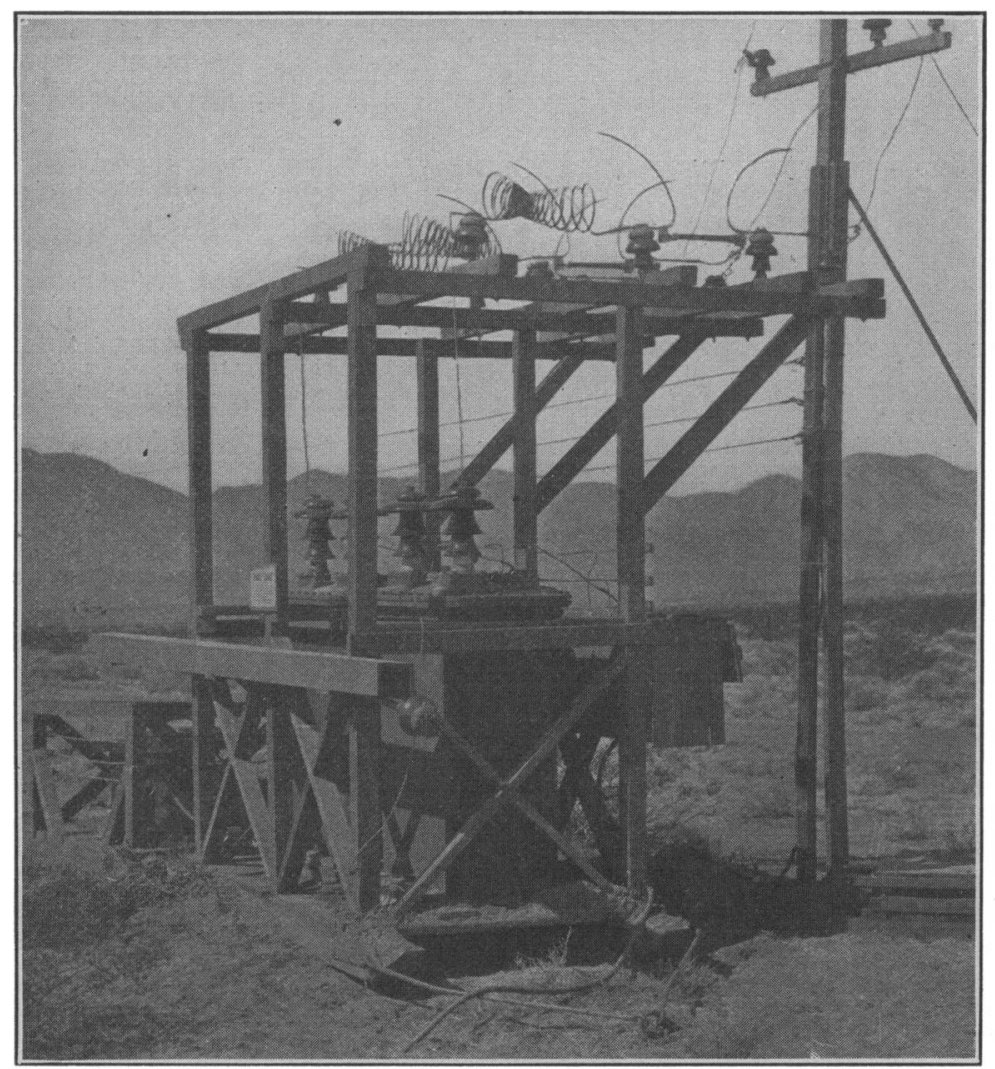

33,000-volt portable substation-outdoor type transformers

excavation, and it was thought at first that the expense of stepping down the voltage, moving transformers, etc., for supplying two or three motors of $7 \frac{1}{2}$ to 10 h.p. each would not be justifiable but the division engineers now insist that the cost of maintaining and operating distillate engines under the conditions experienced along such work is in itself greater than the cost of supplying the electric power, including the charge made against 
them for the energy, as well as the equipment, beyond the transformers; and they further state that the interruptions which they have experienced in concrete work with distillate engines behind a single steam shovel, as compared with what they have experienced in concrete work with electric power behind an electric shovel, has cost them anywhere from $\$ 20$ to $\$ 40$ a day after the engines had been in use a few months and began to develop troubles under those conditions of operation; in other words, the saving is due to the consideration of reliability aside

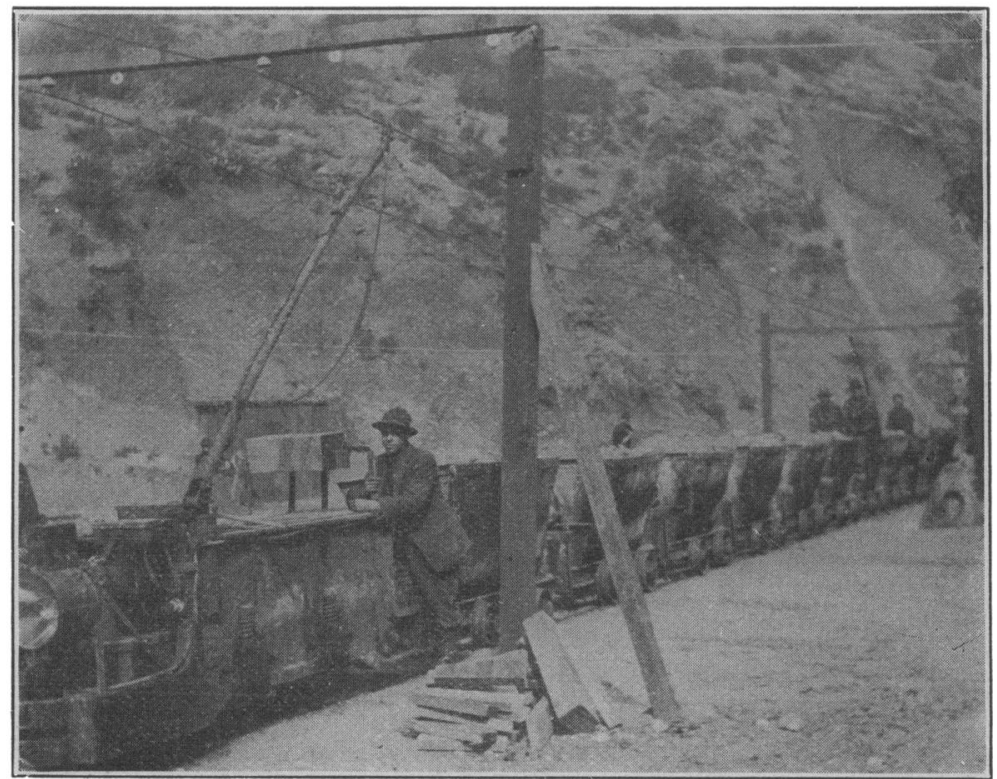

Electric mine locomotive; Elizabeth Lake tunnel

from actual cost of supplying power to the mixers. The cost for tunnel work is considerably reduced and the speed increased by electric lighting. The illustration herewith shows a type of home made cluster, which is giving excellent results at the headings.

\section{Protection Against Gases}

One of the long tunnels in another section runs through an oil district, and at times has developed considerable explosive gases. In order to protect the men against this danger, electric sparking devices have been installed, designed as shown in the illustra- 
tion. They may be operated either by alternating or direct current. They are operated by direct current in this case by means of a switch outside of the tunnel, and as may be seen, are absolutely positive in their action and cannot fail if properly

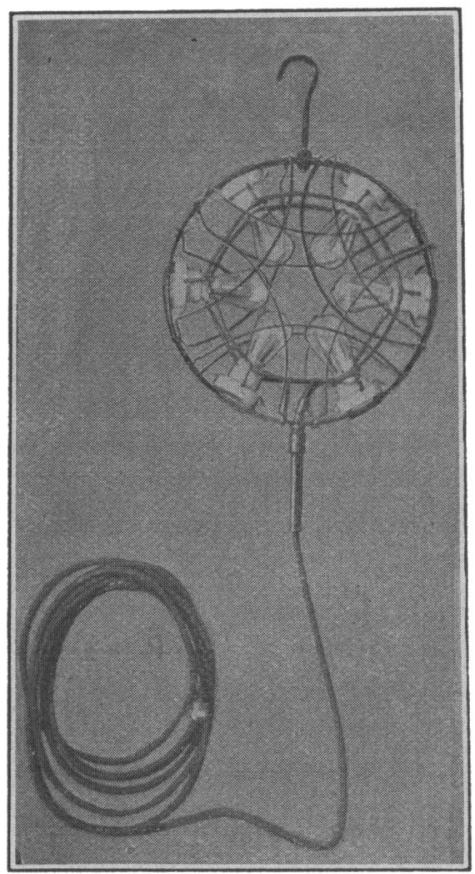

Lamp cluster used in tunnels and designed to reduce lamp breakage from blasting, etc., to a minimum.

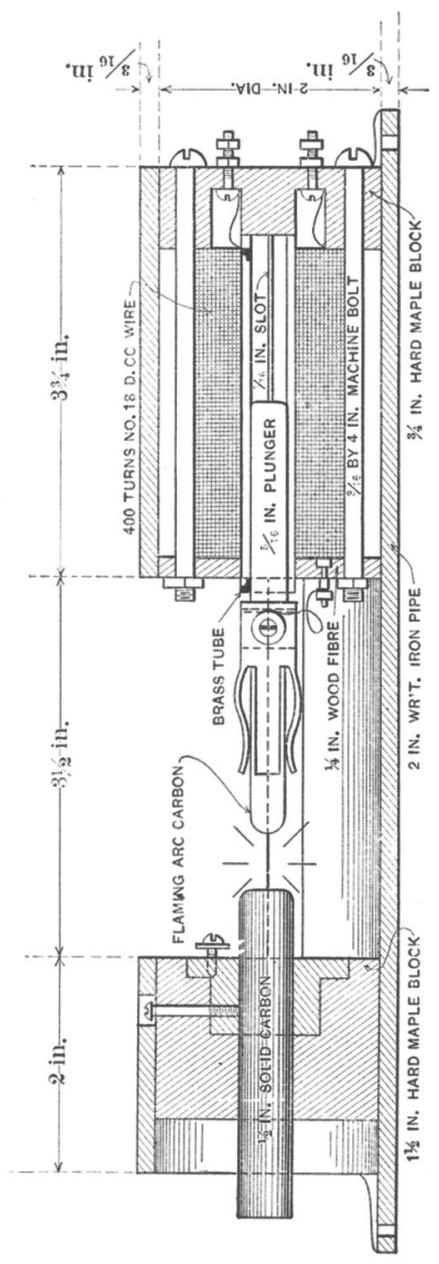

Sparking device for exploding gas in tunnel

trimmed when the miners leave the tunnel. They have exploded gases several times, and in the form shown are usually found intact after the explosion; several of them being in use gives opportunity for further trials before entering the tunnel. 


\section{Amount of Power Required}

A good idea of the amount of power necessary to operate the equipment may be obtained by studying the following tabulation, which gives the total rated motor capacity, approximately 3470 h.p., of the various equipment attached to this system, and the total electrical horse power, approximately 2000 h.p., required at the switch board of the two power plants combined for supplying this system independent of the cement plant. The energy necessary for lighting machine shops and other small requirements is not tabulated, but is included in the power at the switchboard. In many instances power is used 24 hours each day, but in other cases during 16 or 8 hours per day; on an average about 16 hours per day. The amount stated as being required at the switchboard is taken from the heavy load periods during the day; in other words, the average peak load for that work. The average load during the 24 hours would be about 60 per cent of this.

\section{Motor Installation Intake to Pinto Hills}

2 suction dredges....................... 400 h.p.

1 dipper dredge, $1 \frac{1}{2}$-yard dipper . . . . . . . . . . . . . 100

4 electric shovels, $\frac{3}{4}$-yard dippers . . . . . . . . . . . . 300 “

Tufa regrinding mill .................... 200 "

Haiwee dam, hydraulic work . . . . . . . . . . 100 "

8 air compressors, $500 \mathrm{cu}$. ft. each .............. 800 "

8 motor generators, $80 \mathrm{kw}$. each . . . . . . . . . . . . 1000 "

7 rock crushers, 10 and 20 tons per hour each........ 140 "

28 concrete mixers, 6 and $10 \mathrm{cu}$. ft. per batch....... 280 "

7 blowers, $1350 \mathrm{cu}$. ft. per minute each......... 70 "

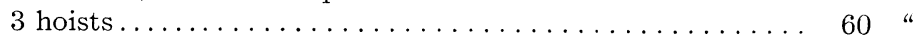

2 pumps...................... 20 "

Total rated capacity of motors .......... 3470 "

The average power used at each end of the Elizabeth tunnel, already described, is $88 \mathrm{kw}$. during the 24 hours, divided, as follows: $5 \frac{1}{2} \mathrm{kw}$. for lighting outside the tunnel; $35 \frac{1}{2} \mathrm{kw}$. for operating the motor-generator which supplies power for ventilation, electric locomotives, lighting the tunnel and a small amount of pumping from the tunnel; and $47 \mathrm{kw}$. for compressed air for drilling, machine shop, camp water supply, etc. The average peak is about double the average load.

\section{Telephone System}

The telephone system is considered not only one of the most profitable adjuncts to the aqueduct construction, but one which 
is essential to its economic construction at reasonable speed. It consists of approximately 260 miles of main line from the Los Angeles offices to the intake, built of two No. 10 copper wires strung on redwood poles, at a cost of $\$ 188$ per mile. This line is divided in three sections by two exchanges, which more than doubles its efficiency. In addition to this there are local telephone systems in each of the various divisions along the work; some of these have as high as 26 telephones. Each local system may be temporarily connected with the main line by a switch in the division engineer's office, there being but one main line telephone on each division. As the telephone system is to be used by all classes of men, very few of them familiar with electrical work, it was though undesirable, if not wholly impossible, to operate it successfully with the line on the power poles. Estimates showed that by making the poles on the transmission line five feet shorter, the telephone line could be placed on separate redwood poles at an equal or slightly less cost, and this has been done. The telephone lines are in every case placed underground at crossings with high-tension electric lines. 